\title{
Architecture from South East Europe in the Scopus Database (1962 - 2015)
}

\author{
Sasha Tasic ${ }^{1}$, Aleksandar Petanovski ${ }^{{ }^{*}}$, Ivo Spiroski ${ }^{2}$ \\ ${ }^{1}$ Faculty of Architecture, Ss Cyril and Methodius University of Skopje, Skopje, Republic of Macedonia; ${ }^{2} I D$ Design \\ 2012/DOOEL Skopje, Skopje, Republic of Macedonia
}

\section{Citation: Tasic S, Petanovski A, Spiroski I. Architecture from South East Europe in the Scopus Database (1962 - 2015). SE 10.3889/ Des. 2016 Jan 26, 2016:10017. hip \\ Key words: architecture; Scopus database; citation metrics; South East Europ \\ Correspondence: Aleksandar Petanovski. Faculty of Architecture, Ss Cyril and Methodius University of
Skopie,Republic \\ dar.petanovski@hotmail.com \\ Received: 29-Nov-2015; Revised: 15-Dec-2015; Accepted: 10-Jan-2016; Published: 26-Jan-2016 \\ Copyright: ๑) 2016 Sasha Tasic, Aleksandar Petanovski, Ivo Spiroski. This is an open-access article distributed under the terms of the Creative Commons Attribution License, which permits unrestricted use, distribution, and reproduction in any medium, provided the original author and source are credited. competing interests exis.}

\begin{abstract}
AIM: The aim of this study was to analyse current scientific impact of published papers about architecture from South East Europe in the Scopus database (1962-2015).

MATERIAL AND METHODS: Document search of the Scopus database was performed on October 13, 2015 about architecture in the Scopus Database (1962-2015). A total number of 572,489 documents worldwide were identified with "architecture" in the title, abstract or keywords. By limitation to South East European countries (Albania, Bosnia and Herzegovina, Bulgaria, Croatia, Cyprus, Greece, Kosovo, Moldova, Macedonia, Montenegro, Romania, Serbia, Slovenia, Turkey, and Italy) only 42,356 documents were separated (7.4\% of all documents). Selected documents were analyzed by year, source, author, country/territory, document type, and subject area.
\end{abstract}

RESULTS: From the total number of 572,489 documents worldwide, only 42,356 documents or $7.4 \%$ of all documents were defined as regional from the South East Europe. The biggest number of published papers was published in Proceedings of SPIE the International Society of Optical Engineering. Top three authors were: Benini L, Sciuto D, and Soudris D. Authors affiliated to Politecnico di Milano published the biggest number of papers about architecture. The waist of papers in the period of 1962 to 2015 from architecture in the Scopus Database was published by the authors from Italy, Greece, United States, and Turkey. Half of the published papers were conference paper. Computer Science was the most often subject with $45.9 \%$ of all papers, engineering was on the second place with $43.7 \%$, and mathematics with $11.6 \%$.

CONCLUSION: Authors and officials of the academic institutions in South East European countries, dealing with architecture, should prepare more scientific papers in academic journals which are indexed in Scopus database.

\section{Introduction}

The South East Europe area is the most diverse, heterogeneous and complex transnational area in Europe, made up of a broad mix of countries. The emergence of new countries and with it the establishment of new frontiers has changed the patterns of political, economic, social and cultural relationships.

Southeast Europe or South Eastern Europe is a geographical and political region of Europe, consisting primarily of the Balkan Peninsula. Sovereign states that are generally included in South Eastern Europe are, in alphabetical order, Albania, Bosnia and Herzegovina, Bulgaria, Croatia, Cyprus,
Greece, Kosovo, Moldova, Macedonia, Montenegro, Romania, Serbia, Slovenia, and partially Turkey and Italy [1].

The area has been undergoing a fundamental change in economic and production patterns following the 1990 changes. Scholarly journals in the post communistic countries were mainly organized and financed by the governmental institutions with the local members of editorial boards, without significant implementation of international standard, mainly published on classical paper technology, without electronic publishing, as well as with closed system of authors and readers.

In order to develop regional journal which cover South East European Countries, it is useful to 
analyse the present situation of the articles publishing the subject of Architecture in the scientific databases.

More than 57 million records are included in Scopus, which includes: over 21,000 peer-reviewed journals, of which approximately 3,800 are full open (see the journal title list); over 360 trade publications; articles-in-press (i.e., articles that have been accepted for publication) from more than 5,000 international publishers, including Cambridge University Press, the Institute of Electrical and Electronics Engineers (IEEE), Nature Publishing Group, Springer, WileyBlackwell and, of course, Elsevier [2]. Scopus includes a more expanded spectrum of journals than Web of Science, and its citation analysis is faster and includes more articles than the citation analysis of Web of Science. On the other hand, the citation analysis that Web of Science presents provides better graphics and is more detailed than the citation analysis of Scopus, probably because Web of Science has been designed with the intention of satisfying users in citation analysis, a field discussed and debated by scientists for decades [3].

Web of Science (WoS), Scopus, and Google Scholar represent different approaches to citation search services. WoS and Scopus are commercial databases (at the expensive end of the spectrum - for good reasons). Google Scholar is currently an open access database, still in beta version after its launch in November 2004 [4]. The three different impact metrics are all based on methodologies developed by external bibliometricians and use Scopus as the data source [5]. Source Normalized Impact per Paper measures contextual citation impact by weighting citations based on the total number of citations in a subject field [6]. The Impact per Publication measures the ratio of citations per article published in the journal [6]. SCImago Journal Rank is a prestige metric based on the idea that not all citations are the same $[7,8]$.

Recently we published results of a total number of 5,808 documents identified with "interior design" in the title, abstract or keywords in the Scopus database. By limitation to South East European countries only 151 documents were separated $(2.6 \%$ of all documents). Selected documents were analyzed by year, source, author, country/territory, document type, and subject area [9].

The aim of this study was to analyze current scientific impact of published papers about architecture from South East Europe in the Scopus database (1962-2015).

\section{Material and Methods}

Article title, abstract, and keywords search of the Scopus database was performed on October 13,
2015 about subject architecture in the Scopus Database (1962-2015).

A total number of 572,489 documents worldwide were identified with "architecture" in the title, abstract or keywords. By limitation to South East European countries (Albania, Bosnia and Herzegovina, Bulgaria, Croatia, Cyprus, Greece, Kosovo, Moldova, Macedonia, Montenegro, Romania, Serbia, Slovenia, Turkey, and Italy) only 42,356 documents were separated (7.4\% of all documents). Selected documents were analyzed by year, source, author, country/territory, document type, and subject area.

\section{Results}

Figure 1 shows that the number of published papers from architecture in the Scopus Database was very small from 1962 to 1988 year. In the next ten years (1989-1999) there was a slow increase and we can see sharp increase from 2013 on (Fig. 1).

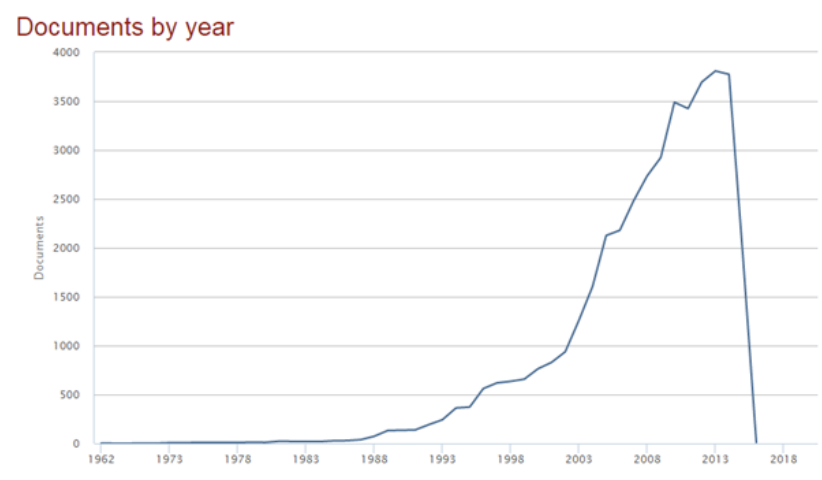

Figure 1: The number of documents by year in architecture from South East Europe in the Scopus Database (1962 - 2015)

The biggest number of published papers from architecture in the South East Europe was published in Proceedings of SPIE the International Society of Optical Engineering with 498 papers.

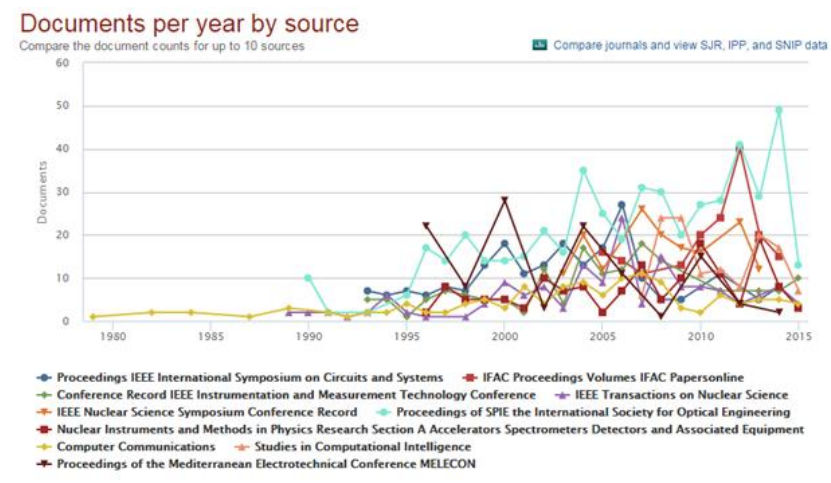

Figure 2: Documents per year by source about architecture from South East Europe in the Scopus Database (1962 - 2015) 
Less than half papers were published in Proceedings IEEE International Symposium on Circuits and Systems (215 papers). The rest of the Journals published 173 and smaller number of papers during the analysed period of time (Fig. 2).

Top three authors from South East Europe which published papers about architecture in the period of 1962-2015 year were: Benini L, (220 papers), Sciuto D, (156 papers), and Soudris D, (142 papers). The rest of top ten authors published between 125 and 81 papers (Fig. 3).

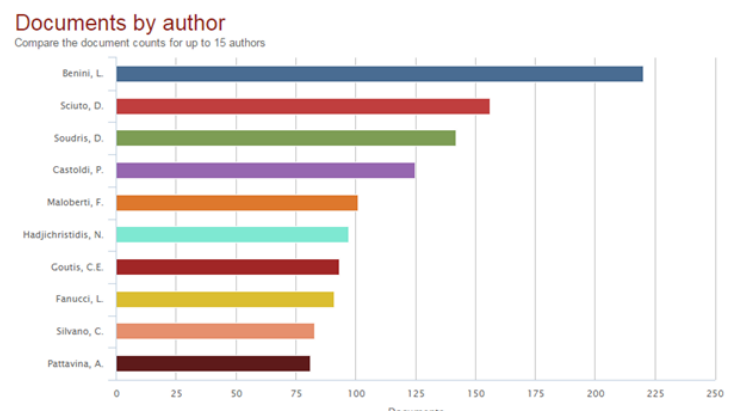

Figure 3: Number of published papers by author about architecture from South East Europe in the Scopus Database (1962 - 2015)

Authors affiliated to Politecnico di Milano published the biggest number of papers about architecture (1,963 papers), on the second place are authors affiliated to Alma Mater Studiorum Universita di Bologna (1,577 papers), and on the third place are authors affiliated to Consiglio Nazionale delle Ricerche with 1,408 papers. The rest of the institutions published less than 1,400 papers about architecture (Fig. 4, top).

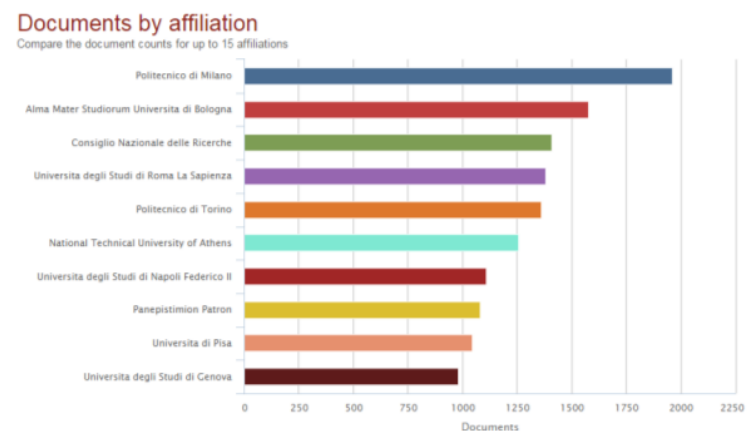

Documents by country/territory

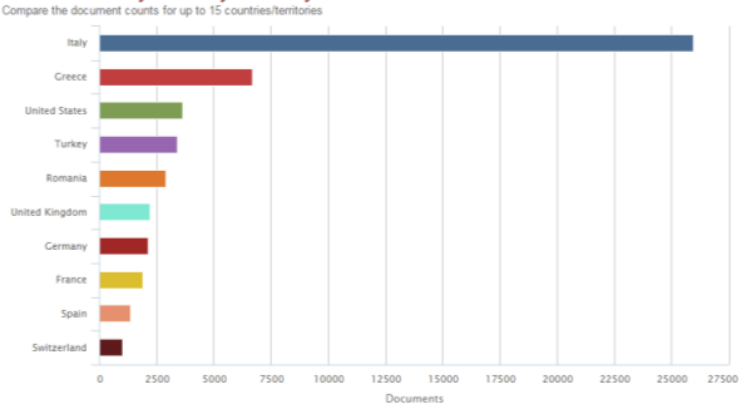

Figure 4: Documents by affiliation (top) and current documents by country (down) about architecture from South East Europe in the Scopus Database (1962 - 2015)
The waist of papers in the period of 1962 to 2015 from architecture in the Scopus Database was published by the authors from Italy (25,962 papers or 6.1\%). Authors from Greece published 6,677 papers from architecture, authors from United States published 3,644 papers and authors from Turkey published 3,413 papers. The rest of the countries published less than 3,000 papers about architecture (Fig. 4, down).

Half of the published papers from architecture in the period of 1962-2015 in South East Europe were conference papers (21,171 papers). Articles were published in $44.4 \%$ or 18,826 papers, review papers were published in $2.8 \%$ (1,205 papers), and the rest of the documents were less than $2 \%$ (Fig. 5, top).
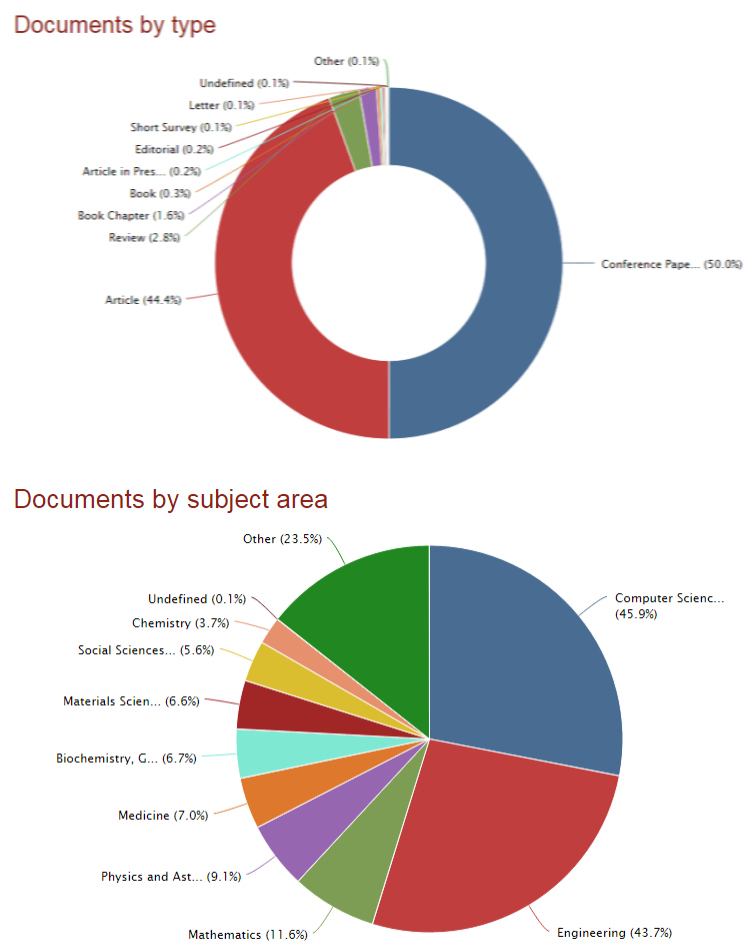

Figure 5: Percentage of documents by type (top) and current percentage of documents by subject area (down) about architecture from South East Europe in the Scopus Database (1962 - 2015)

Computer Science was the most often subject from architecture published in the period from 19622015 with $45.9 \%$ of all papers, engineering was on the second place with $43.7 \%$ (18,505 papers), and mathematics with $11.6 \%$ (4,925 papers). The rest of the subjects were published in less than ten percent of all documents (Fig. 5, down).

\section{Discussion}

We are presenting in this paper analysis of the deposited papers from the fields of architecture in the Scopus database in South East Europe. From the 
total number of 572,489 documents worldwide, only 42,356 documents or $7.4 \%$ of all documents were defined as regional from the South East Europe. The participation of architecture of $7.4 \%$ documents from South East Europe is almost three times bigger than participation of interior design from the identical region (2.6\% of all documents) [9], which means that architecture is far more developed in this region than interior design.

The biggest number of published papers from architecture in the South East Europe was published in Proceedings of SPIE the International Society of Optical Engineering. Less than half papers were published in Proceedings IEEE International Symposium on Circuits and Systems and the rest of the Journals published smaller number of papers during the analysed period of time. Top three authors from South East Europe which published papers about architecture in the period of 1962-2015 year were: Benini L, Sciuto D, and Soudris D.

Authors affiliated to Politecnico di Milano published the biggest number of papers about architecture, on the second place are authors affiliated to Alma Mater Studiorum Universita di Bologna, and on the third place are authors affiliated to Consiglio Nazionale delle Ricerche. The waist of papers in the period of 1962 to 2015 from architecture in the Scopus Database was published by the authors from Italy, Greece, United States, and Turkey. Similarly, most of the papers about Interior Design from South East Europe in the Scopus Database (1977-2015) were published from Italy, Turkey, and Croatia [9], probably because identical institutions and/or authors from the mentioned countries are publishing in both fields of architecture and interior design.

It is very interesting that half of the published papers from architecture in the period of 1962-2015 in South East Europe were conference papers, articles were published in $44.4 \%$, review papers were published in $2.8 \%$, and the rest of the documents were less than $2 \%$. This is in accordance with the published subjects from the architecture. Namely, Computer Science was the most often subject from architecture published in the period from 1962-2015 with $45.9 \%$ of all papers, engineering was on the second place with $43.7 \%$, and mathematics with $11.6 \%$. Contrary to that, in the field of interior design in the South East Europe, most of the documents were articles $(65.6 \%)$, conference papers were published in one quarter $(25.2 \%)$, and reviews were published less than $10 \%$. Subject area medicine was predominant $(34.4 \%)$ followed by engineering $(32.5 \%)$, social sciences $(21.9 \%)$, environmental science $(12.6 \%)$, arts and humanities $(11.9 \%)$, and computer science (11.3\%) [9]. These differences between architecture and interior design in the South East Europe could be as a result of different definitions of the both fields in the Scopus database, as a result of different percentage of applications of these disciplines in general, or as results of different regional activities of architecture and interior design.

There is very small number of published papers presenting the bibliometrics of the subject architecture in the Scopus database. Green roof research is a multidisciplinary and new research area. Bibliometric quantification to assess the rate of publications in specific areas of research for this novel research area based on the scientific literature as available from the Web of Science was conducted [10]. The number of publications in this field increased in the last two decades at very similar pace to other pre-established academic disciplines. It was also found that papers on green roofs were classified into 32 research areas. The distribution of publications between countries has been skewed, with the USA and the EU conducting $66 \%$ of the research, and thus allocation of research effort is focused in those continents and predominantly in temperate ecosystems [10]. However, there has been a sharp increase in the number of countries that conduct green roof research.

Green building has been on the focus of research in the discipline of architecture and engineering in China in the recent years. Bibliometric methods were applied in the paper for a multidimensional study and statistics of the 2781 research papers on green building that were domestically published between 2007 and 2009 based on CNKI China Journal Full-Text Database. The statistics covers such aspects as the distribution of the annual publication of these 2781 articles, distribution of the vehicle journals, distribution of the authors, sources of fund, as well as the authors' working units [11].

In the review article about the Green roof vegetation for North American ecoregions, Dvorak \& Volder, 2010 [12] concluded that as green roofs continue to become regulated and adopted in policy, further development of standards and guidelines is needed. There was no common ground for reporting of green roof research, and they made recommendations for facilitating such efforts for improved research, policy development and their management across North America's diverse ecological regions [12].

One study presents a bibliometric analysis of the world's leading journals focusing on the subject of enterprise architecture in the public administration. The method uses bibiiometric indicators data to generate a map of research for the areas of study, exhibiting existing correlations, based on data of 118 papers cited in leading journals since 1999. This multidisciplinary approach has identified contributions in social sciences, technology and government programs. Indeed, research on enterprise architecture in the public sector is completely correlated with egovernment and interoperability to achieving goals and solving problems in this area [13]. 
Frenken et al., 2009 proposed a research program to analyse spatial aspects of the science system. First, they provide a review of scientometric studies that already explicitly take the spatial dimension into account. The review includes studies on (i) the spatial distribution of research and citations, (ii) the existence of spatial biases in collaboration, citations and mobility, and (iii) the citation impact of national versus international collaborations. Then, they address a number of methodological issues in dealing with space in scientometrics [14].

In summary, we are presenting in this paper analysis of the deposited papers from the fields of architecture in the Scopus database in South East Europe. From the total number of 572,489 documents worldwide, only 42,356 documents or $7.4 \%$ of all documents were defined as regional from the South East Europe. The participation of architecture of 7.4\% documents from South East Europe is almost three times bigger than participation of interior design from the identical region $(2.6 \%$ of all documents), which means that architecture is far more developed in this region than interior design.

\section{References}

1. Hösch, Nehring, Sundhaussen (Hrsg.), Lexikon zur Geschichte Südosteuropas, S. 663, ISBN 3-8252-8270-8

2. Bakkalbasi N, Bauer K, Glover J, Wang L. Three options for citation tracking: Google Scholar, Scopus and Web of Science. Biomed Digit Libr. 2006;3:7.

http://dx.doi.org/10.1186/1742-5581-3-7

3. Falagas ME, Pitsouni El, Malietzis GA, Pappas G. Comparison of PubMed, Scopus, Web of Science, and Google Scholar: strengths and weaknesses. FASEB J. 2008;22(2):338-42. http://dx.doi.org/10.1096/fi.07-9492LSF

4. Jacso P. As we may search-Comparison of major features of the Web of Science, Scopus, and Google Scholar citation-based and citation-enhanced databases. Current Science-Bangalore. 2005; 89(9):1537.

5. http://www.journalmetrics.com/

6. Moed HF. Measuring contextual citation impact of scientific journals. Journal of Informetrics. 2010;4(3):265-277.

http://dx.doi.org/10.1016/i.joi.2010.01.002

7. González-Pereira B, Guerrero-Bote VP, Moya-Anegón F. A new approach to the metric of journals' scientific prestige: The SJR indicator. Journal of Informetrics. 2010;4(3):379-391. http://dx.doi.org/10.1016/i.joi.2010.03.002

8. Guerrero-Bote VP, Moya-Anegón F A further step forward in measuring journals' scientific prestige: The SJR2 indicator. Journal of Informetrics. 2012;6(4):674-688.

http://dx.doi.org/10.1016/j.joi.2012.07.001

9. Nikoljski Panevski E, Petanovski A, Spiroski I. Published Papers about Interior Design from South East Europe in the Scopus

Database (1977 - 2015). South East European Journal of

Architecture and Design. 2015.10007. http://dx.doi.org/10.3889/seejad.2015.10007

10. Blank L, Vasl A, Levy S, Grant G, Kadas G, Dafni A, Blaustein L. Directions in green roof research: A bibliometric study. Building and Environment. 2013;66:23-28.

http://dx.doi.org/10.1016/i.buildenv.2013.04.017
11. Gui Z-G, Li B, Zhao X-C. Focus of research on green building A bibliometric analysis based on the 2781 papers domestically published between 2007 and 2009. Xi'an Jianzhu Keji Daxue Xuebao/Journal of Xi'an University of Architecture and Technology. 2010;42(3):451-456.

12. Dvorak B, Volder A. Green roof vegetation for North American ecoregions: A literature review. Landscape and Urban Planning. 2010;96(4):197-213.

http://dx.doi.org/10.1016/j.landurbplan.2010.04.009

13. Ramos KHC, De Sousa Junior RT. Bibliometric analysis of enterprise architecture in the public administration. Information (Japan). 2015;18(2):501-519.

14. Frenken K, Hardeman S, Hoekman J. Spatial scientometrics: Towards a cumulative research program. Journal of Informetrics. 2009;3(3):222-232.

http://dx.doi.org/10.1016/j.joi.2009.03.005 